\title{
Observed Solar Cycle Variation of the Stratospheric QBO Generated in the Mesosphere and Amplified by Upward Propagating Waves
}

\author{
Hans G. Mayri1,2, Frank T. Huang³, Jae N. Lee ${ }^{4,5}$ \\ ${ }^{1}$ Johns Hopkins University Applied Physics Laboratory, Laurel, USA \\ ${ }^{2}$ Emeritus, NASA Goddard Space Flight Center, Greenbelt, USA \\ ${ }^{3}$ Emeritus, University of Maryland, Baltimore County, USA \\ ${ }^{4}$ University of Maryland, Baltimore, USA \\ ${ }^{5}$ NASA Goddard Space Flight Center, Greenbelt, USA \\ Email: hans.mayr@jhuapl.edu, hmayr2@verizon.net, fthuang@verizon.net,jae.n.lee@nasa.gov
}

How to cite this paper: Mayr, H.G., Huang, F.T. and Lee, J.N. (2018) Observed Solar Cycle Variation of the Stratospheric QBO Generated in the Mesosphere and Amplified by Upward Propagating Waves. Atmospheric and Climate Sciences, 8, 63-83. https://doi.org/10.4236/acs.2018.81005

Received: November 26, 2017

Accepted: January 9, 2018

Published: January 12, 2018

Copyright (c) 2018 by authors and Scientific Research Publishing Inc. This work is licensed under the Creative Commons Attribution International License (CC BY 4.0).

http://creativecommons.org/licenses/by/4.0/

\begin{abstract}
With an analysis of zonal wind observations over 40 years, Salby and Callaghan [1] showed that the Quasi-biennial Oscillation (QBO) at $20 \mathrm{~km}$ is modulated by 11-year solar cycle (SC) variations from about 12 to $20 \mathrm{~m} / \mathrm{s}$ (Figure 2). The observations are reproduced qualitatively in a study with the $3 \mathrm{D} \mathrm{Nu}-$ merical Spectral Model, which shows that the SC effect of the stratospheric $\mathrm{QBO}$ is produced by dynamical downward coupling originating in the mesosphere. In this modeling study, the SC period is taken to be 10 years, and a realistic heat source is applied varying exponentially with altitude: $0.2 \%$, surface; $2 \%, 50 \mathrm{~km} ; 20 \%, 100 \mathrm{~km}$ and above. The numerical results show that the variable solar radiation in the mesosphere around $65 \mathrm{~km}$ generates a hemispheric symmetric Equatorial Annual Oscillation (EAO), which is modulated by relatively large SC variations. Under the influence of wave mean flow interactions, the EAO propagates into the lower atmosphere and is the dynamical source or pacemaker for the large SC modulation of the QBO. The numerical results show that the upward propagating small-scale gravity waves from the troposphere amplify the SC modulations of the QBO and EAO in the stratosphere, part of the SC mechanism. The zonal winds of the equatorial QBO and EAO produce through the meridional circulation measurable $\mathrm{SC}$ variations in the temperature of the stratosphere and troposphere at high latitudes. Analysis of NCEP temperature and zonal wind data (1958 to 2006) provides observational evidence of the $\mathrm{EAO}$ with $\mathrm{SC}$ variations around 11 years.
\end{abstract}




\section{Keywords}

Quasi-Biennial Oscillation (QBO), Observed Solar Cycle Variations, Modeling Study, Equatorial Annual Oscillation (EAO), Dynamical Downward

Coupling, Wave Mean-Flow Interactions, Non-Linear Interactions

\section{Introduction}

In several papers, the Quasi-biennial Oscillation (QBO) of the zonal circulation in the stratosphere around the equator has been linked observationally to solar cycle (SC) effects.

Following a study by Holton and Tan [2], Labitzke [3] [4] and Labitzke and van Loon [5] [6] discovered that the temperatures at northern polar latitudes in winter are positively and negatively correlated with the SC when the QBO is in its westward and eastward phase, respectively. Dunkerton and Baldwin [7] and Baldwin and Dunkerton [8] also found evidence of a correlation between the SC and phase of the $\mathrm{QBO}$ in the northern stratosphere.

The SC connection between the QBO and temperature variation in the polar region has been simulated in modeling studies. Matthes et al. [9] inserted rocketsonde data into their GCM to produce realistic QBO wind fields around the equator. With fixed eastward and westward QBO zonal winds for both solar maximum and solar minimum conditions, the model reproduces qualitatively the observed SC variations that characterize the polar stratosphere in winter. The SC signatures at northern polar latitudes were also reproduced with a GCM [10] that simulates the QBO zonal winds with parameterized small-scale gravity waves.

The solar cycle (SC) variations in the temperature at polar latitudes are related to the phase of the $\mathrm{QBO}$, and $\mathrm{SC}$ signatures are observed in the zonal winds near the equator where the QBO is generated. Salby and Callaghan [1] analyzed 40 years of zonal winds from radiosonde observations in the lower stratosphere at equatorial Kanton Island and Singapore, provided by the Free University of Berlin (FUB) for the years from 1956 to 1996. From the intersections of the wind directions in the time variations of the monthly mean zonal winds at $20 \mathrm{~km}$ (45 $\mathrm{mb}$ ), they determined the length of the westerly phase of the QBO. And this showed that the westerly phase is 3 to 6 months longer during solar minimum than solar maximum. With the longer data record between 1950 and 2001 from FUB, Hamilton [11] reexamined the observed variations in the length of the period for the $\mathrm{QBO}$ zonal winds. The observations at $50 \mathrm{hPa}$ confirmed the quasidecadal oscillation [1] but showed that the SC signature is not as clear in the longer 51-year data record. Between 1996 and 2001, the length of the QBO westerly increases with solar activity, in opposite phase to the preceding 40-year variations. Fischer and Tung [12] analyzed the data record of the lower stratosphere (70 to $15 \mathrm{hPa}$ ) from 1953 to 2007, based on Singapore observations pro- 
vided by FUB. In this analysis, the Continuous Wavelet Transform [13] was applied that generates the length of the QBO period in the zonal winds. Consistent with the results for the westerly phase presented by Salby and Callaghan [1] and Hamilton [11], the derived length of the QBO period peaks during the solar minima in 1955, 1965, 1976 and 1986, but varies in opposite direction after 1996 with a sharp peak during the SC maximum in 2000.

Salby and Callaghan [1] also analyzed the SC modulation of the QBO amplitude, which is the focus of the present paper. With the 40-year monthly data record (1956 to 1996$)$ at $45 \mathrm{mb}(20 \mathrm{~km})$ supplied by FUB, they carried out a Fourier analysis to record the magnitude of the SC modulated zonal winds. In Figure 1 the power spectrum is shown for the zonal winds near the equator plotted versus frequency in cycles per year (cpy). The dominant peak at $0.41 \mathrm{cpy}$ is the signature of the mean QBO period of about 29 months, and the smaller amplitudes near 0.5 and 0.59 cpy are the SC signatures of 11 and 5.5 years, respectively. To reveal the variability of the $\mathrm{QBO}$, the spectrum was band-pass filtered $(0.34-0.62$ cpy $)$-and the results are presented in Figure 2 for the variations of the zonal wind power $\left(\mathrm{m}^{2} / \mathrm{s}^{2}\right)$ along with the $10.7-\mathrm{cm}$ solar flux. Shown in Figure 2, the inferred SC variations of the zonal winds are relatively large. The zonal wind power varies from about 150 to $400 \mathrm{~m}^{2} / \mathrm{s}^{2}$ between solar minimum and maximum, corresponding to velocities from about 12 to $20 \mathrm{~m} / \mathrm{s}$. As expected, the variations in Figure 2 show a delay in the QBO wind velocities relative to the 10.7 solar flux, but only during the first two solar cycles. During the following cycles around 1981 and 1991 without apparent delay, the atmosphere was perturbed by volcanic aerosols from the eruptions of El Chichon in 1982 and Pinatubo in 1991 that likely interfered with the SC forcing.

Salby and Callaghan [14] showed with an analysis of NCEP data covering 45 years that the QBO temperature variations at low latitudes are strongly correlated with the SC in support of their earlier findings. The 11-year SC signatures in the zonal wind and temperature variations have also been identified in 40

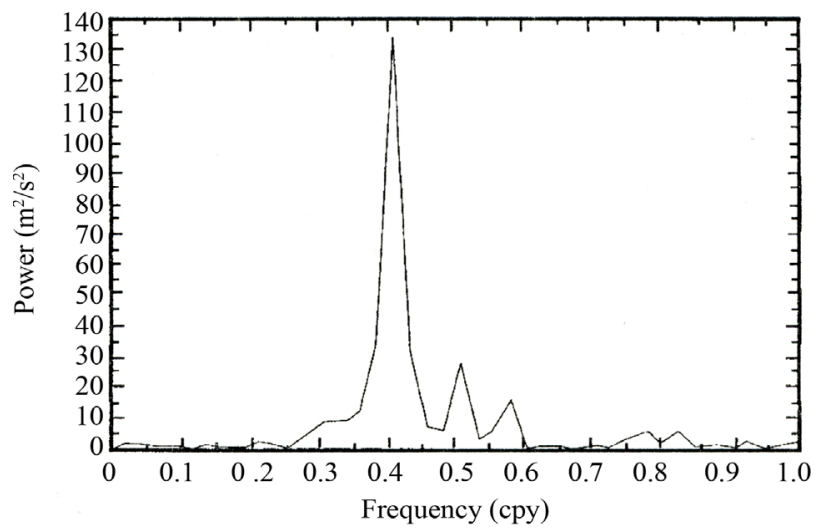

Figure 1. Power spectrum of zonal winds from 1956 to 1996 at $45 \mathrm{mb}(20 \mathrm{~km})$, supplied by the Free University of Berlin (FUB) (Figure taken from Salby and Callaghan [1], with permission from the American Meteorological Society). 


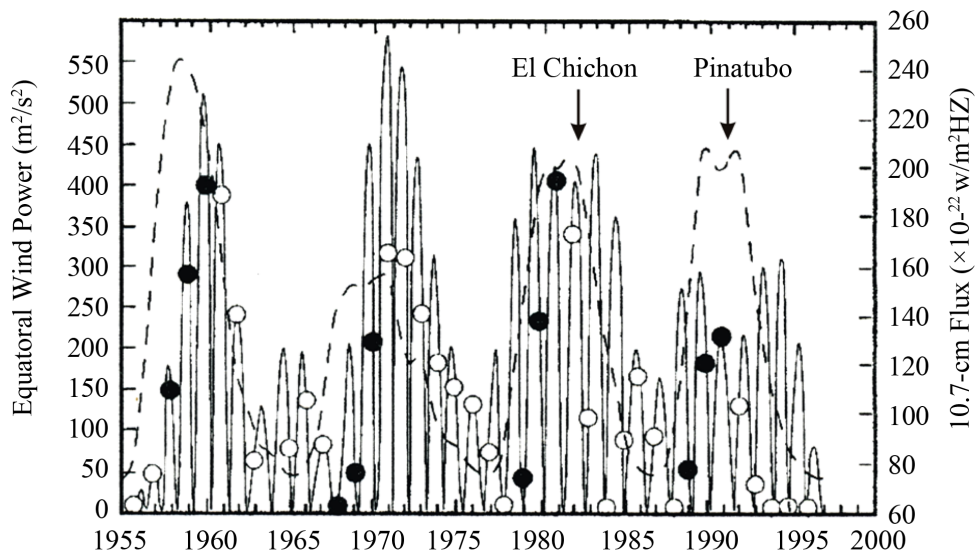

Figure 2. Time variation of the zonal wind power $\left(\mathrm{m}^{2} / \mathrm{s}^{2}\right)$ generated with the synthesis of the frequency band $(0.34-0.62 \mathrm{cpy})$ in the power spectrum of Figure 1. With dashed line, the $10.7 \mathrm{~cm}$ flux is shown for comparison (Figure taken from Salby and Callaghan [1], with permission from the American Meteorological Society).

years of European Centre for Medium-Range Weather Forecasts (ECMWF) reanalysis (ERA-40) data [15].

With a 2D model of the middle atmosphere, accounting for photo chemistry and dynamics, McCormack [16] carried out a 50-year computer run to simulate the observed QBO variations. Allowing for the UV solar cycle variations in the upper stratosphere, the model produces a 28-month QBO, in which the length of the westerly phase is reduced (as observed) and the easterly phase is enhanced during solar maximum relative to solar minimum. Palmer and Gray [10] also showed that their GCM produces longer QBO periods during solar minimum. Cordero and Nathan [17] conducted a study with a $2 \frac{1}{2} 2 \mathrm{D}$ model extending from about 15 to $30 \mathrm{~km}$, in which the QBO is driven by prescribed Kelvin and Rossby gravity waves. In this model, the feedback from the SC induced variations of ozone influences the wave interaction to generate a SC modulation of the QBO amplitude, which varies in phase with the observed zonal winds reported by Salby and Callaghan [1]. The SC effects in the atmosphere have been studied with the NCAR Whole Atmosphere Community Climate Model (WACCM), which is a chemistry climate model that extends from the surface to the lower thermosphere. Matthews et al. [18] carried out a series of 20-year experiments with the WACCM3 model to study under the influence of the QBO the SC response of temperature and ozone in the middle atmosphere and its impact on the troposphere. The QBO was prescribed by adjusting the zonal winds to reproduce the observed durations of the eastward and westward phase. Kren et al. [19] carried out with the WACCM CESM model an extensive study with 40year-period simulations for the industrial era starting in 1850. The SC variations are generated in the stratosphere by the absorption of solar radiation in ozone, and the QBO is generated internally with parameterized inertial gravity waves that are controlled by the Coriolis force. With that analysis, the durations and 
amplitudes of the eastward and westward phase of the QBO produce no significant differences for the solar maximum and minimum years.

The observed SC modulation of the QBO in the stratosphere (Figure 2), presented by Salby and Callaghan [1], has been the impetus for a study with the 3D Numerical Spectral Model [20] [21] [22] that is reviewed and summarized in the present paper. It shows that the SC effect is spawned in the mesosphere. The variations in the UV radiation at higher altitudes generate in the zonal circulation a SC-modulated 12-month Equatorial Annual Oscillation (EAO). Amplified by wave interactions, the EAO propagates into the lower atmosphere and is the dynamical source for the SC modulation of the QBO.

Analysis of zonal wind data supplied by the National Centers for Environmental Prediction (NCEP) provides observational evidence for the EAO [23] [24] [25]. And the EAO is observed varying with the F10.7 cm solar flux [26].

The processes that generate the $\mathrm{QBO}$ and $\mathrm{EAO}$ with $\mathrm{SC}$ variations have in common that they are controlled by the unique dynamical properties of the equatorial region: 1) Without Coriolis force and related meridional circulation, the wave forcing is very efficient because it is only dissipated by the eddy viscosity [27]. As a result, the $\mathrm{QBO}$ and $\mathrm{EAO}$ zonal winds peak at the equator. 2) The eddy viscosity produces in the stratosphere time constants on the order of years, which controls in part the QBO period and favors the generation of SC related long-term variations.

\section{Numerical Spectral Model}

The Numerical Spectral Model (NSM) is fully nonlinear but is a mechanistic model without topography and ocean atmosphere interaction. The model was introduced by Chan et al. [28] [29] and Mengel et al. [30], and it has been applied to simulate and understand the dynamical features of the middle atmosphere e.g., [31] [32].

Discussed in considerable detail [22], the present 3D model is formulated in terms of vector spherical harmonics with zonal and meridional wave numbers limited to $\mathrm{m}=4$ and $\mathrm{l}=12$, respectively. Applying homogeneous boundary conditions, and with the initial conditions set to zero for all state variables, the model is integrated from the surface to $130 \mathrm{~km}$ with a small vertical step size of about $0.5 \mathrm{~km}$.

An integral part of the NSM is that it incorporates the Doppler Spread Parameterization (DSP) for small-scale gravity waves (GW) developed by Hines [33] [34] [35] [36]; its application in the model is discussed in the appendix of Mayr et al. [37]. The DSP employs a spectrum of waves that interact with each other to produce Doppler spreading, which affects the interactions with the flow-of critical importance for generating the QBO. In the present model, a GW source is adopted that is isotropic, time independent, and peaks at the equator. The DSP is applied in the model under conservation of GW momentum, which requires that the nonlinear processes are accounted for that produce the interactions be- 
tween the GW and background winds. This requires that the model is integrated with a short time step close to 5 minutes to achieve convergence with Newtonian iteration. With an adjustable parameter, the DSP provides isotropic eddy diffusion rates, increasing with altitude, which is incorporated into the model under the assumption that the global variations can be ignored. In the present mechanistic model, the planetary waves are generated internally by instabilities without an imposed excitation source Mayr et al. [38]. The dynamical conditions around the tropopause, in part due to GW interactions, contribute significantly to the planetary waves in the middle atmosphere with amplitudes comparable to those observed. The model does not account for the planetary waves that are generated in GCMs by topography and convection.

In Figure 3 the computed monthly mean zonal wind velocities are shown near the equator, which are generated with the current 3D Numerical Spectral Model. With a period of about 23 months, the amplitude of the QBO at $30 \mathrm{~km}$ is close to $20 \mathrm{~m} / \mathrm{s}$, and at $50 \mathrm{~km}$ the 6 -month Semi-annual Oscillation is generated with velocities greater than $30 \mathrm{~m} / \mathrm{s}$.

\section{Solar Cycle Modulated QBO}

In the modeling study discussed here Mayr et al. [21], the solar cycle (SC) period is taken to be 10 years, and a realistic SC heat source is applied. The relative amplitude of the SC source increases exponentially with altitude: $0.2 \%$, surface; $2 \%$, $50 \mathrm{~km} ; 20 \%, 100 \mathrm{~km}$ and above; illustrated in Figure 4(a).

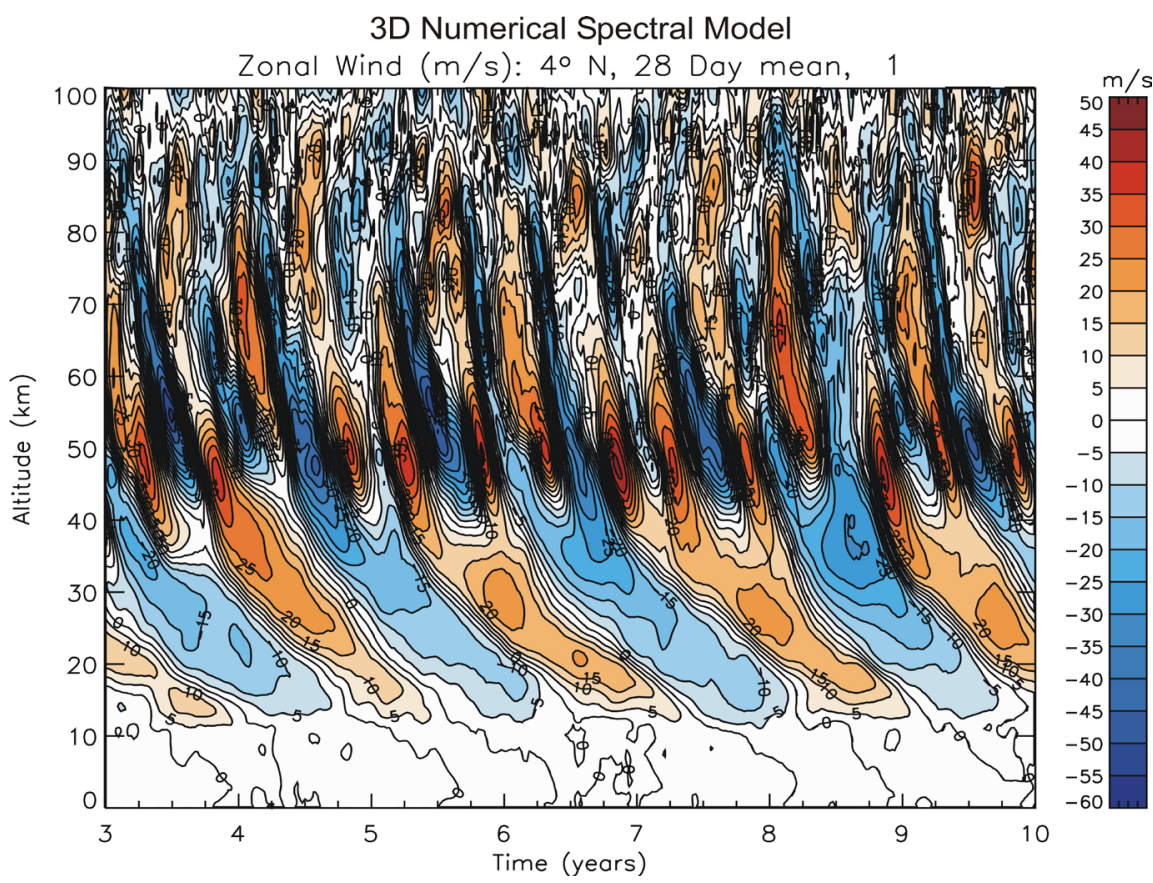

Figure 3. Monthly average of computed zonal winds near the equator at $4^{\circ}$ latitude (Gaussian point). With a period of almost 24 months, the amplitude of the Quasi-biennial Oscillation (QBO) is close to $20 \mathrm{~m} / \mathrm{s}$ at $30 \mathrm{~km}$. Higher-up, the Semi-annual Oscillation (SAO) dominates with amplitudes exceeding $30 \mathrm{~m} / \mathrm{s}$ (Figure taken from Mayr et al. [21], in color). 


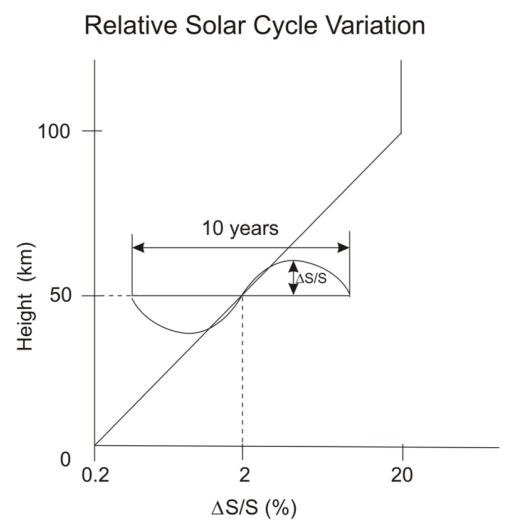

Quasi-biennial Oscillation (QBO)

(a)

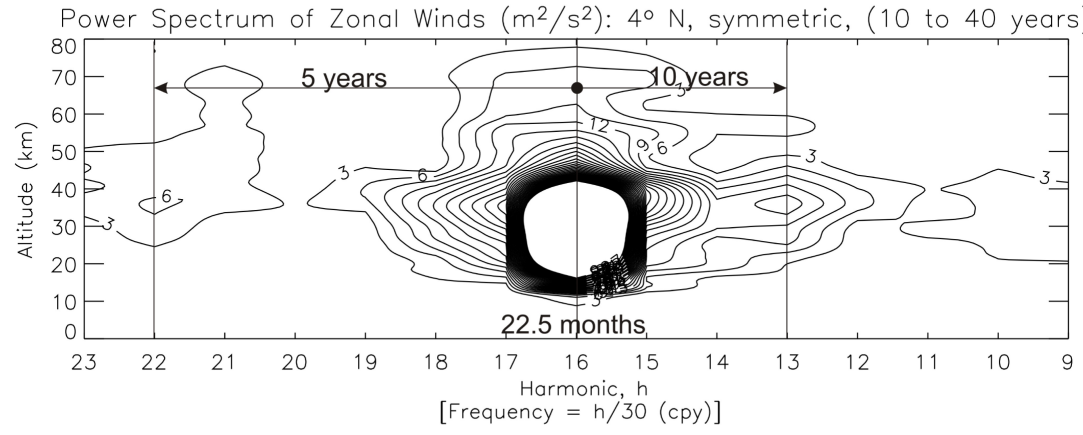

(b)

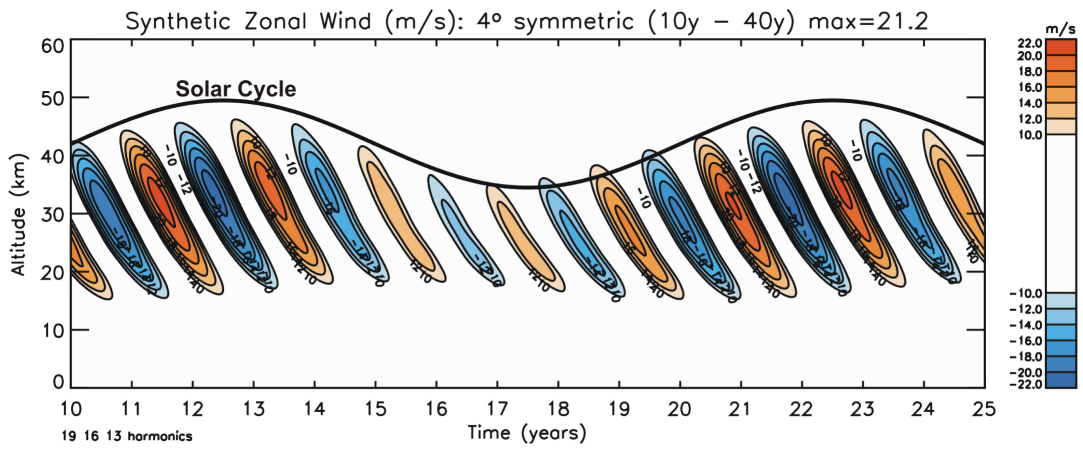

(c)

Figure 4. (a) Height profile for the relative amplitude of the solar cycle (SC) variation on a logarithmic scale. The period of the SC variation is taken to be 10 years, constant throughout the entire model run; (b) Power spectrum at $4^{\circ}$ latitude for the hemispheric symmetric component of the computed zonal winds in terms of discrete Fourier harmonics, $h$, which are related to the frequency, h/years (cycles per year, cpy). The time span for the analysis is 30 years, ignoring the first 10 years to account for spin-up. With harmonic $h=16$, the dominant QBO period is 22.5 months (i.e., 360/16). The side lobe at $h=13$ describes the 10-year SC modulation identified with the arrow, and at $h=22$ is the 5-year oscillation; (c) To reveal the SC modulation of the QBO for the 30-year time span, the dominant QBO harmonic at $h=16$ is synthesized with the side lobes that describe the 10 -year SC signature, i.e., $h=16$ with $h=16 \pm 3$. The contour interval is $2 \mathrm{~m} / \mathrm{s}$, and the lowest contours are $10 \mathrm{~m} / \mathrm{s}$ to reveal more readily the magnitude of the amplitude modulation. With solid line, the phase of the 10-year SC forcing is shown for comparison (Figure taken from Mayr et al. [21], with color). 
In Figure 4(b) the spectrum is shown for the hemispheric symmetric zonal wind component at $4^{\circ}$ latitude taken from a computer run from 10 to 40 years. The amplitudes are presented in terms of Fourier harmonics, h, instead of frequencies. With that notation, the spectrum is dominated by the QBO signature at $h=16$ for the period of 30/16 (years) $=22.5$ months. And the spectral features, identified with horizontal arrows, display the SC signatures of the 10- and 5 - year oscillations at $h=13(16-3)$ and $h=22(16+6)$, respectively.

We note parenthetically, that the product between variations with frequency, $\omega$, in complex notation, $A \exp \left[i \omega_{a} t\right]$ and $\operatorname{Bexp}\left[i \omega_{b} t\right]$, generates the oscillations $C_{1}$ $\exp \left[i\left(\omega_{a}+\omega_{b}\right) t\right]$ and $C_{2} \exp \left[i\left(\omega_{a}-\omega_{b}\right) t\right]$. With discrete Fourier harmonics, h, the nonlinear interaction between $\mathrm{QBO}$ and 10- or 5-year SC forcing, for example, can be readily identified in the spectra from the additions and subtractions of integers, i.e., $\omega_{a} \pm \omega_{b} \rightarrow h_{a} \pm h_{b}$.

In Figure 4(c) is shown the SC modulation of the QBO generated with a synthesis of the spectral features for $h=16$ and $h=13$ (16 - 3), including also the amplitude at $h=19(16+3)$. With solid line the phase of the 10-year SC heating is shown for comparison. From Figure 4(c) it is apparent that the magnitude of the SC modulation is relatively large. The QBO amplitude increases from about 12 to $20 \mathrm{~m} / \mathrm{s}$, in phase with the SC forcing and in qualitative agreement with the observations shown in Figure 2 [1].

The above discussed QBO zonal wind velocities peak at the equator. Away from the equator, the oscillation is dissipated by the meridional circulation, which generates SC variations in the temperature at high latitudes. In Figure 5(a) the temperature spectrum is shown at $84^{\circ}$ latitude. A sharp amplitude maximum is generated at $h=16$ for the QBO period of 22.5 months, and the 10 year SC signatures are pronounced at $h=13$ and 19 (16 \pm 3$)$. The synthesis of the spectral features is presented in Figure 5(b). It shows that the computed SC modulation of the $\mathrm{QBO}$ is pronounced in the lower stratosphere, and is relatively large in the troposphere below $10 \mathrm{~km}$ with values close to $1 \mathrm{~K}$ during solar maximum.

\section{Solar Cycle Modulated Equatorial Annual Oscillation (EA0)}

The QBO is generated in the model with a large SC modulation (Figure 4(c)). And the question is how the SC effect is transferred to the QBO.

The 10-year SC forcing must go through the seasonal variations, and the Semi-annual Oscillation (SAO) seemed to be the answer. Like the QBO, the SAO peaks at the equator and is amplified by wave interactions. And in their seminal theory for the QBO, Lindzen and Holton [27] invoked the SAO to seed the QBO. But a numerical search for SC signatures in the SAO proved the effect to be weak and erratic.

The model generates a 12-month annual oscillation in the zonal winds, which is modulated with a pronounced SC variation [20]. Unlike the dominant anti- 


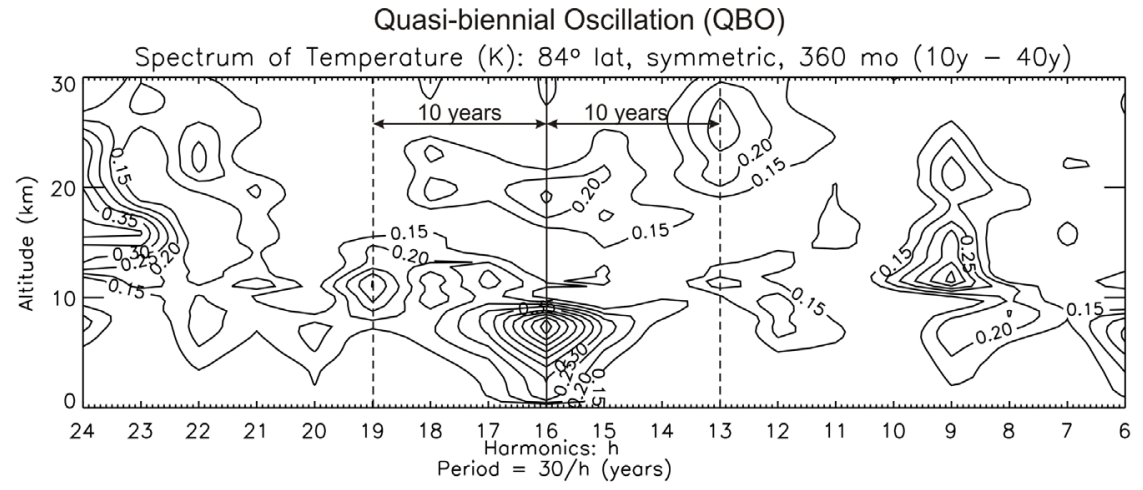

(a)

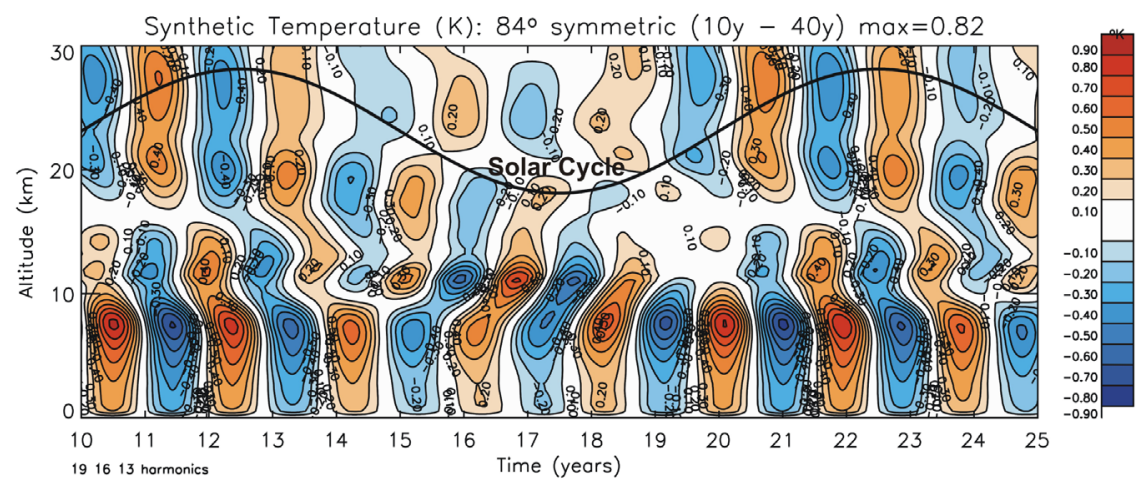

(b)

Figure 5. (a) Similar to Figure 4(b) but for the temperature variations of the QBO at $84^{\circ}$ latitude (Gaussian point); (b) The synthesized spectral features show the 10-year SC modulation in phase with the solar forcing (Figure taken from Mayr et al. [21], with color).

symmetric annual oscillation over the summer and winter hemispheres, this annual oscillation is hemispheric symmetric and confined to equatorial latitudes like the QBO, a first in the literature; it is therefore referred to as Equatorial Annual Oscillation (EAO).

In Figure 6(a) the spectrum is presented for the hemispheric symmetric component of the zonal winds (EAO) at $4^{\circ}$ latitude. The large amplitude peak at $h=30$ is the 12-month annual oscillation. And the SC signatures are shown at $h$ $=33(30+3)$ for the 10 -year oscillation and at $h=24(30-6)$ for the 5 -year second harmonic, both identified with arrows. The spectral features of the EAO extend into the upper mesosphere, in contrast to the QBO confined to the lower stratosphere (Figure 4(b)).

In Figure 6(b) the synthesis is presented for the spectrum of the 10-year SC modulation of the EAO, $h=30$ with $h=30 \pm 3$. The EAO slowly propagates down with a velocity of about $3 \mathrm{~km} /$ month, confirmed by observations e.g., [25]. The SC modulation of the EAO is very large in the upper stratosphere around 45 $\mathrm{km}$, and it is in phase with the SC and with the QBO variation (Figure 4(c)). Apparently, the EAO is guiding and stimulating the SC modulation of the QBO, a pivotal role of the SC mechanism discussed. As shown in Figure 6(c), the 


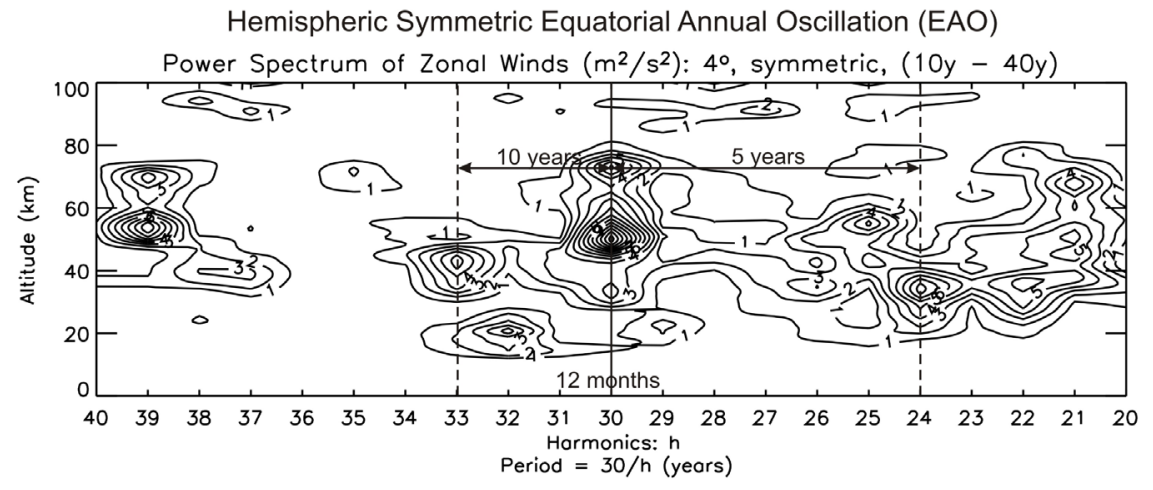

(a)

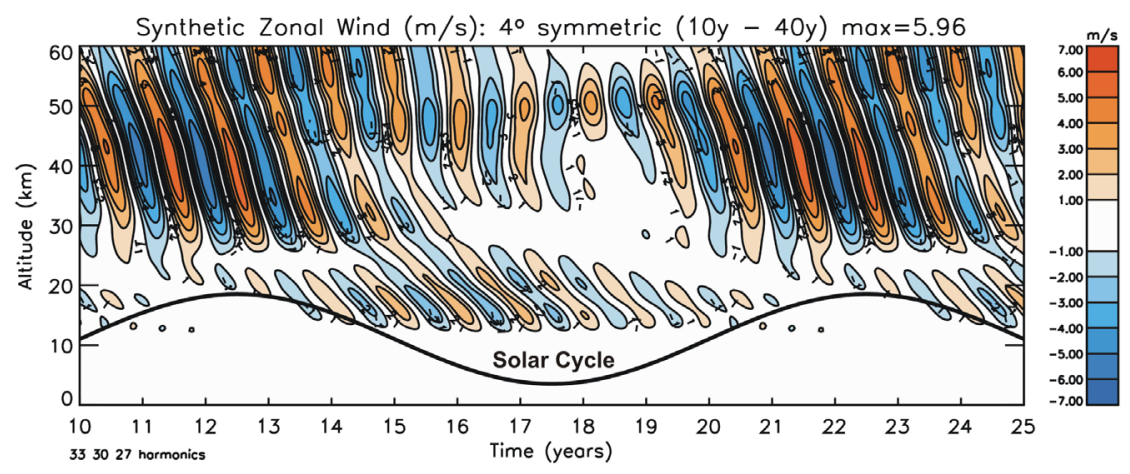

(b)

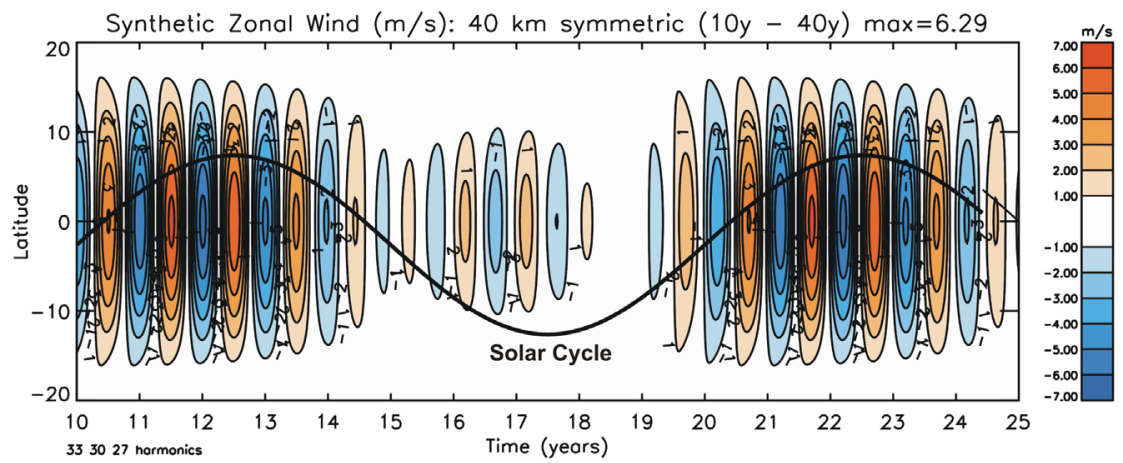

(c)

Figure 6. (a) Similar to Figure 4(b) but for the symmetric 12-month Annual Oscillation (AO) near the equator. The oscillation is modulated by the SC, shown in the 10- and 5year side lobes that are identified in the spectrum; (b) The phase of the synthesized SC modulation agrees with that of the QBO (Figure 4(c)), which indicates that the symmetric $\mathrm{AO}$ is the pacemaker; (c) The SC modulated symmetric AO peaks at the equator, therefore referred to as Equatorial Annual Oscillation (EAO) (Figure taken from Mayr et al. [20], with color).

SC-modulated EAO peaks at the equator and virtually disappears at latitudes above $20^{\circ}$.

Like the SC-modulated QBO, the EAO produces temperature variations in the polar region generated by the meridional circulation. The temperature spectrum in Figure 7(a) shows that the signature of the 12-month annual oscillation (AO) at $h=30$ is weak, but the 10 -year SC modulation at $h=27$ is pronounced. The 


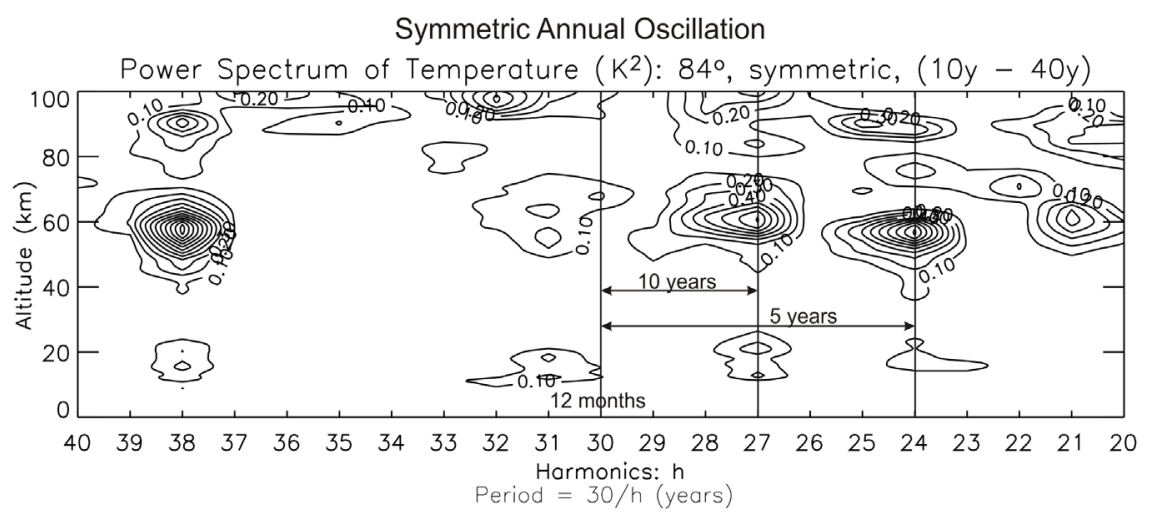

(a)

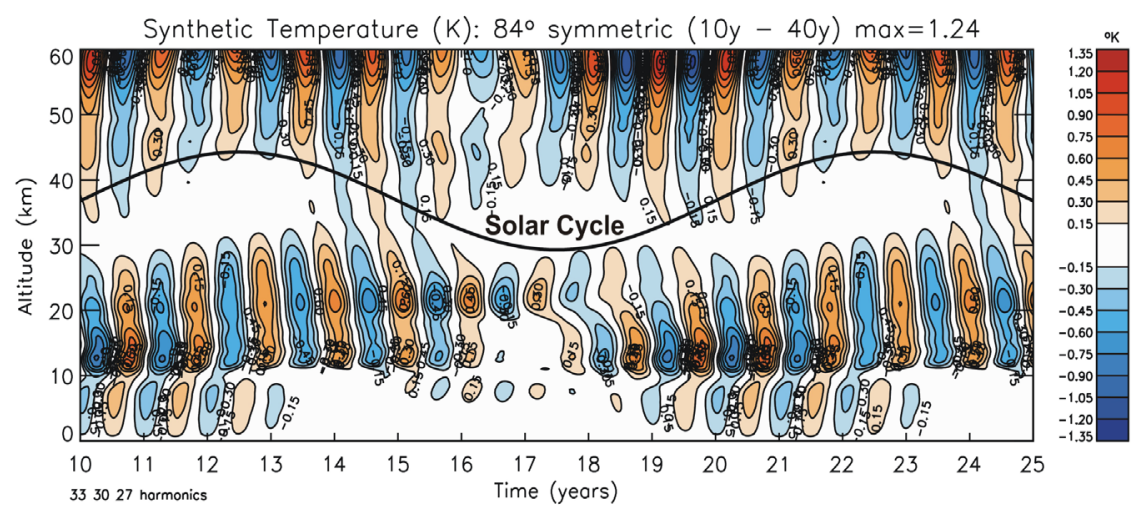

(b)

Figure 7. Similar to Figure 5 but for the symmetric AO in the temperature variations at high latitudes (Figure taken from Mayr et al. [20], with color).

synthesis of the spectrum in Figure $7(\mathrm{~b})$ shows that the symmetric AO propagates down from the mesosphere to produce temperature variations around $1 \mathrm{~K}$ near the tropopause, in phase with the SC forcing.

\section{Solar Cycle Mechanism}

\subsection{Generation of SC-Modulated EAO}

What is the mechanism that generates the SC-modulated Equatorial Annual Oscillation (EAO) in the model? Addressing this question [22], Figure 8(a) shows the spectrum for the anti-symmetric component of the zonal winds at $11^{\circ}$ latitude extending into the upper mesosphere. Two regimes are presented. In the range, $0<h<9$, the spectral features are shown for the SC signatures of the 10year oscillation at $h=3$ and the 5-year component at $h=6$, which are generated around $65 \mathrm{~km}$. And the peak in the Fourier spectrum at $h=30$ covers the dominant 12-month annual oscillation between the summer and winter hemispheres.

The anti-symmetric 10-year SC oscillation of the zonal winds at $60 \mathrm{~km}(h=3$, Figure 8(a)) is presented in Figure 8(b), plotted versus latitude. Generated with the weak SC heat source in the model (Figure 4(a)), the velocities are small. Non-linear interactions in the mesosphere between this 10 -year anti-symmetric 


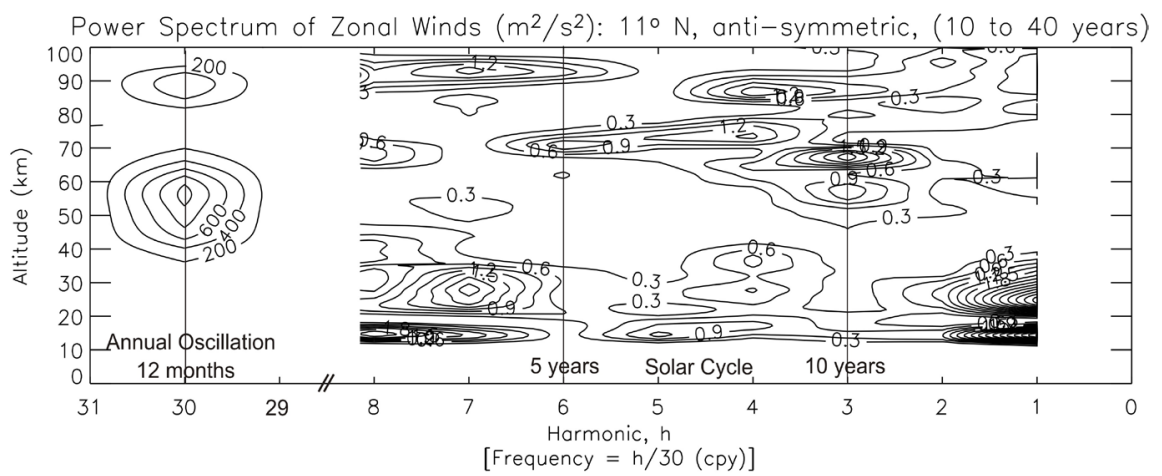

(a)

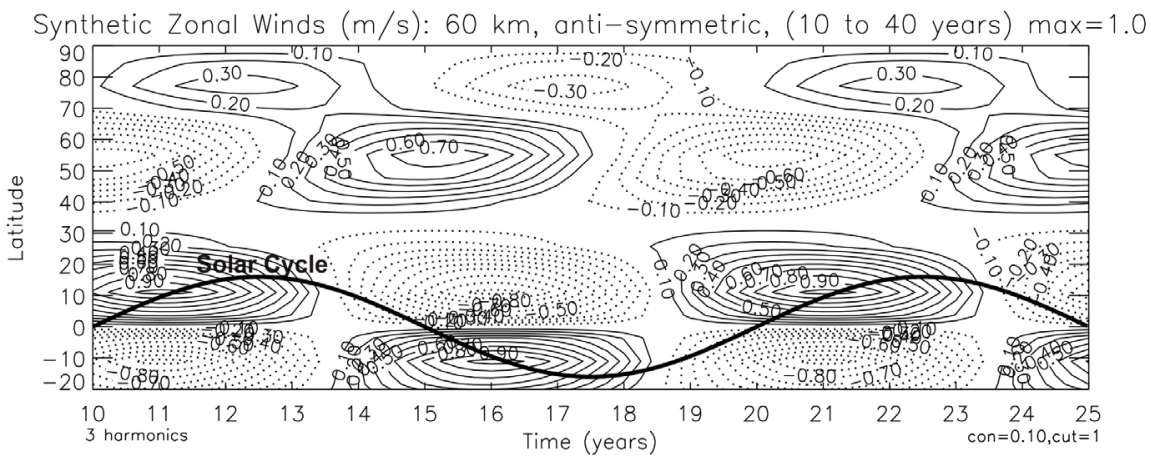

(b)

Figure 8. (a) Spectrum of the hemispheric anti-symmetric zonal wind component reveals the 10-year SC signature at $h=3$, which peaks at $65 \mathrm{~km}$. Also shown is the spectral feature of the dominant anti-symmetric 12-month annual oscillation (AO) at $h=30$; (b) Latitude pattern of the anti-symmetric 10-year SC oscillation of zonal winds at $60 \mathrm{~km}$; with solid line, the phase of the SC forcing is shown for comparison (Figure taken from Mayr et al. [22]).

SC oscillation and the dominant anti-symmetric annual oscillation $(h=30$; Figure 8(a)) can produce the hemispheric symmetric SC-modulated EAO shown in Figure 6 which is the source and origin of the large SC variations generated in the model.

\subsection{Amplification by Wave Interaction}

Gravity wave (GW) interactions with the zonal winds play a central role in generating the $\mathrm{QBO}$ and $\mathrm{EAO}$ at equatorial latitudes. Shown in a numerical study [22], the GW momentum source (MS) further increases the SC modulations of the equatorial oscillations. In this analysis, the wave MS is normalized at each altitude to a dimensionless maximum value of 10 , which preserves the relative SC variations.

The spectral features for the wave MS of the QBO at $h=16$ and $h=16 \pm 3$ (not shown) are mirror images of the zonal wind oscillations. With a synthesis of the spectrum, the MS for the QBO is presented in Figure 9(a). It shows that the MS varies by about a factor of 2 at $40 \mathrm{~km}$, in phase with the solar forcing.

The spectrum for the MS of the EAO also produces the salient features that 


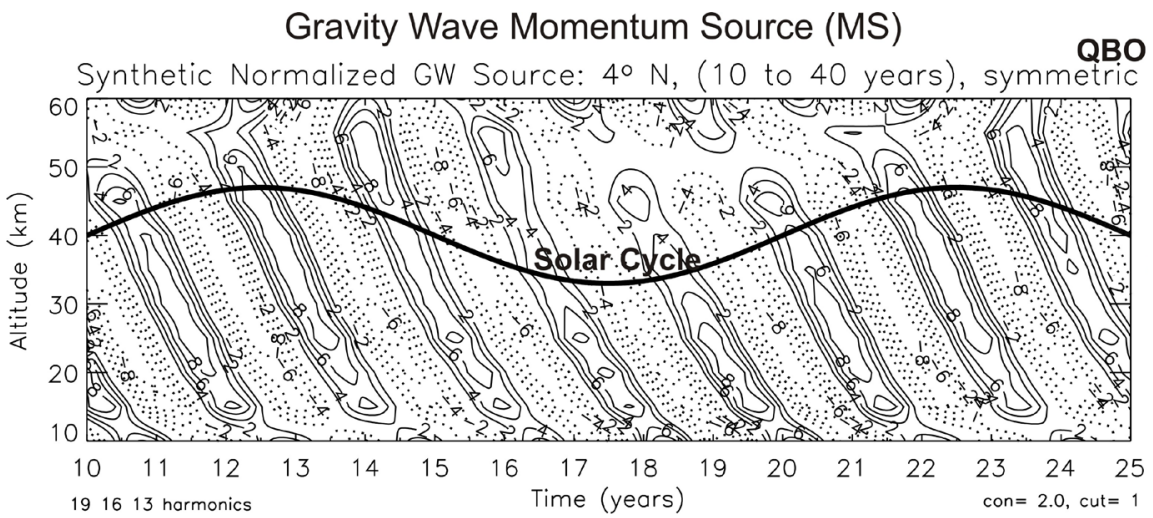

(a)

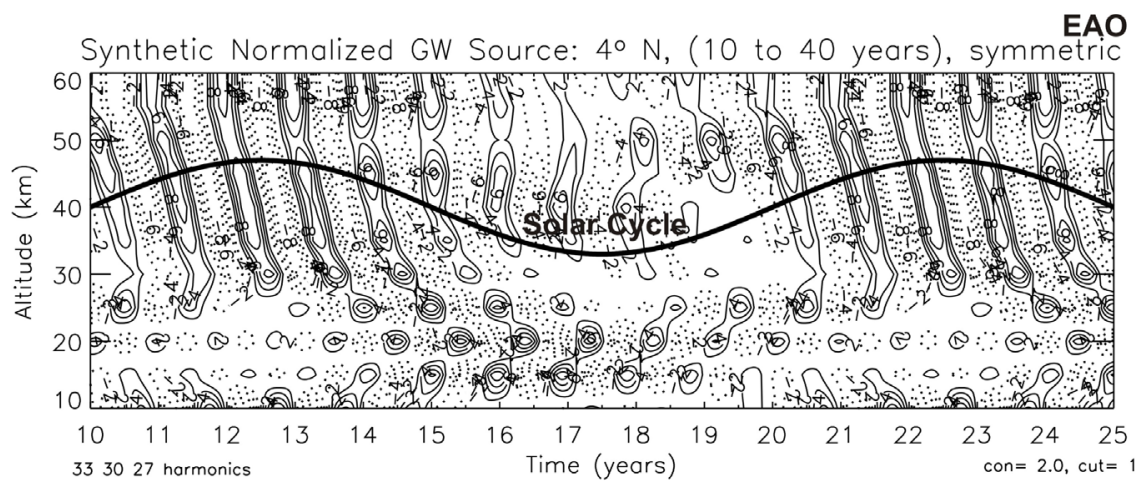

(b)

Figure 9. Gravity wave momentum source (MS) for the time span from 10 to 40 years. The wave MS increases exponentially with altitude and is normalized at each height to a dimensionless maximum value of 10 , which preserves the time-dependent relative SC modulation of the source. (a) Synthesis for the QBO spectral features of the MS shows that a pronounced amplitude modulation is generated, in phase with the zonal winds (Figure 4(c)) and with the imposed SC forcing. With contour intervals of 2, the maximum amplitudes are close to 10, and the minimum values are around 5; (b) Similar to (a) but for the normalized MS that amplifies the symmetric Equatorial Annual Oscillation (EAO). The MS varies by about a factor of 4 , in phase with the SC and with the zonal winds (Figure 6(b)) (Figure taken from Mayr et al. [22]).

describe the SC modulation of the zonal winds, and the synthesis of the spectrum is presented in Figure 9(b). It shows that the MS varies with the SC by about a factor of 4 at $40 \mathrm{~km}$.

The upward propagating small-scale GW amplify the SC modulations of the $\mathrm{QBO}$ and EAO, part of the SC mechanism.

The above-discussed mechanism shows that the following processes are involved in generating the SC modulation of the stratospheric QBO: (1) Solar forcing produces in the mesosphere a 10-year SC oscillation $(h=3$, Figure 8(a)), which is hemispheric anti-symmetric (opposite phase in the two hemispheres). (2) Non-linear interactions between this anti-symmetric SC oscillation and the large and dominant anti-symmetric 12-month annual oscillation $(h=30$, Figure 8(a)) can produce the symmetric SC modulated Equatorial Annual Oscillation (EAO) shown in Figure 6. (3) Like the QBO, the symmetric EAO propagates 
down into the lower atmosphere under the influence of wave interactions that amplify the zonal wind oscillations. (4) And gravity wave interactions amplify the SC modulations of the QBO (Figure 9(a)) and EAO (Figure 9(b)). (5) The wave amplified EAO is the dynamical source and pathway for the large SC modulation of the QBO in the lower stratosphere, in qualitative agreement with the observations shown in Figure 2 [1].

\section{Solar Cycle Modulated NCEP Equatorial Annual Oscillation (EA0)}

The temperature and zonal wind variations supplied by the National Centers for Environmental Prediction (NCEP) provide observational evidence for the SC modulated EAO [26].

In this review of the earlier study, the NCEP data are employed from the National Center for Atmospheric Research (NCAR) Reanalysis R-1 [39], which cover the years from 1958 to the present. The R-1 data represent the zonal-mean temperature and zonal wind variations extending from the surface to $31 \mathrm{~km}$, which are produced by balloon-borne radiosonde observations assimilated with GCM simulations [39] [40]. Satellite measurements after 1978 improved the global coverage, but produced a jump in the NCEP temperatures near the tropopause and around $31 \mathrm{~km} \mathrm{[41]} \mathrm{[42].}$

The latitudinal variations of the NCEP data are delineated in terms of the hemispheric symmetric and anti-symmetric components. For the northern (n) and southern (s) hemispheres respectively, the $D_{n}$ and $D_{s}$ data are split up into symmetric (S) and anti-symmetric (A) components by computing respectively DS = $\left(D_{n}+D_{s}\right) / 2$, and $D A_{n}=\left(D_{n}-D_{s}\right) / 2, D A_{s}=\left(D_{s}-D_{n}\right) / 2$. The DS component describes the $\mathrm{QBO}$ and $\mathrm{SAO}$, and the present $\mathrm{EAO}$, which peak at the equator. And $D A_{n}=-D A_{s}$ describes the dominant anti-symmetric 12-month annual oscillation (AO) with opposite phase in the two hemispheres, which vanishes at the equator.

The NCEP data discussed cover the years from 1958 to 2006. For this time span, the amplitude spectrum of the F10.7 flux is dominated by the harmonics $\mathrm{h}$ $=4$ and 5 (Figure 10(a)), corresponding to SC periods of 12 and 9.6 years respectively. Fourier analysis shows that the SC periods appear in the hemispheric symmetric equatorial annual oscillation of the zonal winds (Figure 10(b)), mainly below $20 \mathrm{~km}$. In the temperature spectrum at the pole (Figure 10(c)), the SC signatures are pronounced and extend from about 10 to $25 \mathrm{~km}$.

In Figure 11(a) is shown the monthly $10.7 \mathrm{~cm}$ flux from 1958 to 2006 together with a synthesis of the dominant harmonics, $h=4$ and 5 , which produce a distinct pattern of variable maxima and minima. Commensurate with the format in Figure 6(b) for the EAO model results, we present in Figure 11(b) for the 48-year NCEP data the synthesis of the zonal wind harmonics, $h=48$ with (48 \pm 4) and (48 \pm 5 ), identified in Figure 10(b). It shows that a coherent modulation pattern is generated below about $18 \mathrm{~km}$. The filtered wind modulations near 14 $\mathrm{km}$ (solid line) reproduce remarkably well the solar cycle variability in Figure 11(a). With almost constant phase difference, the variable maxima and minima 
F10.7 Amplitude Spectrum: [1958-2006]

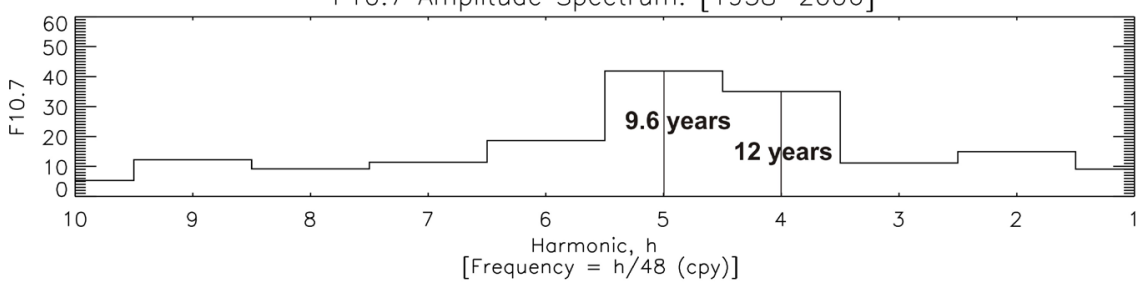

(a)

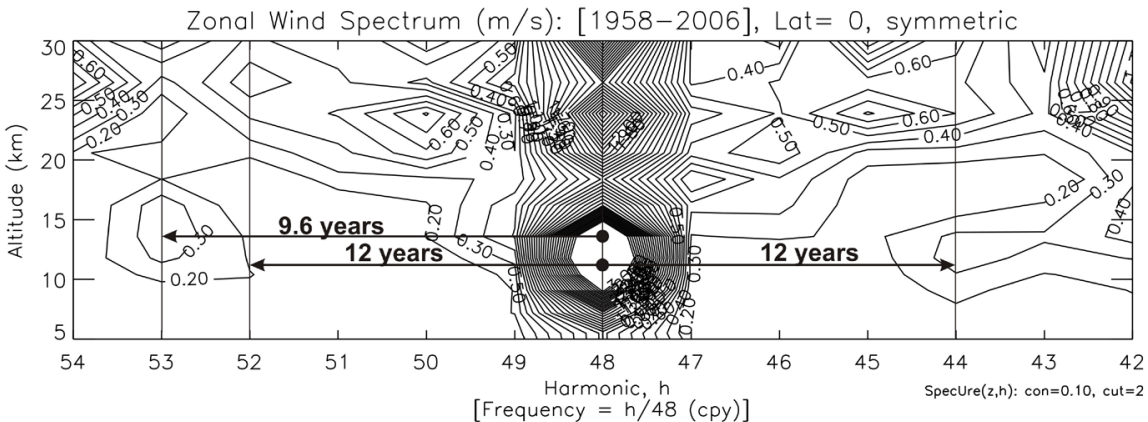

(b)

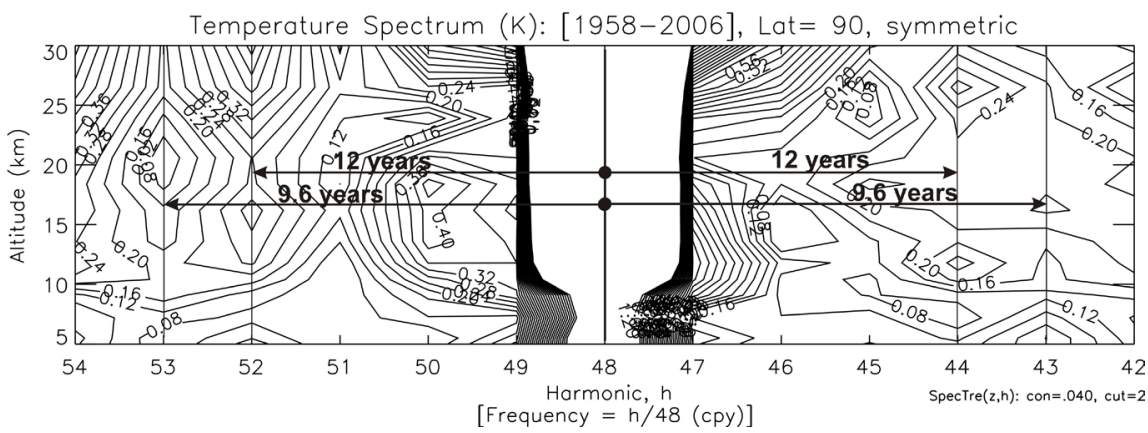

(c)

Figure 10. (a) Spectrum for the F10.7 monthly solar flux from 1958 to 2006, with the dominant Fourier harmonics $h=4$ and 5 for the periods of 12 and 9.6 months, respectively; (b) Symmetric zonal wind spectrum at the equator for the NCEP data; (c) Analogous to (b) but showing the symmetric temperature spectrum at the pole. The modulation periods are indicated with arrows (Figure taken from Mayr et al. [26]).

in the NCEP zonal winds mimic those of the solar cycle. Above $18 \mathrm{~km}$ however, the modulation pattern in Figure 11(b) is highly variable and has no resemblance to the solar flux index. The filtered AO temperature modulations in the polar region are presented in Figure 11(c) and show that around $10 \mathrm{~km}$ there is a resemblance to the $\mathrm{SC}$ variability. At the pole, the variations are much larger than those generated at the equator (see Figure 6(c) of Mayr et al. [26].

\section{Summary and Conclusions}

Salby and Callaghan [1] have shown from an analysis of 40 years of zonal wind measurements that the QBO in the lower stratosphere is modulated by a large 11-year solar cycle (SC) variation in phase with the $10.7 \mathrm{~cm}$ solar flux (Figure 2).

The SC variation of the QBO is reproduced in the present modeling study that is 


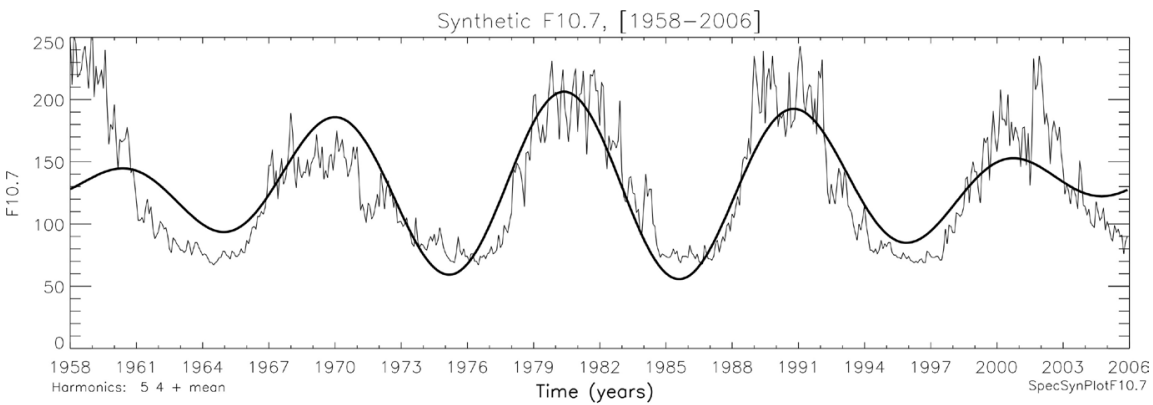

(a)

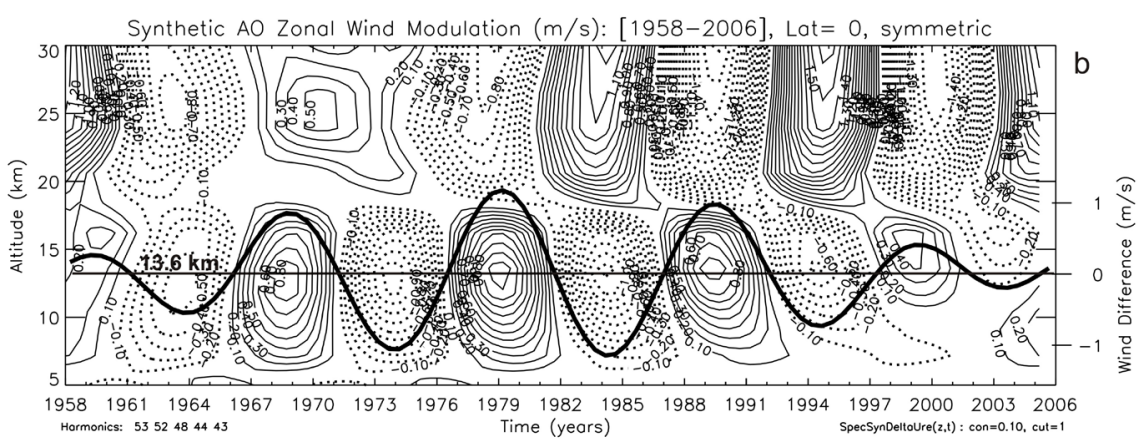

(b)

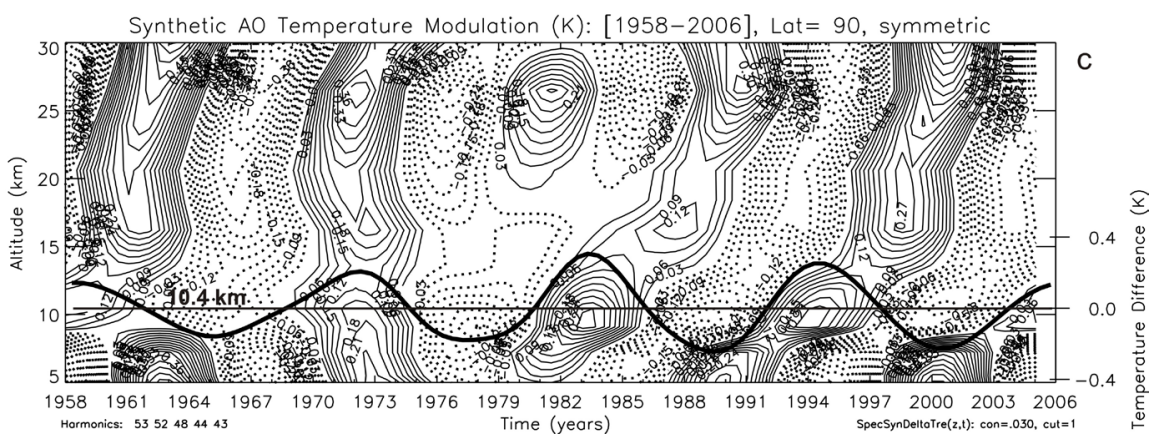

(c)

Figure 11. (a) Monthly $10.7 \mathrm{~cm}$ flux shown together with the synthesized variations employing the harmonics $h=4$ and 5 for the periods of 12 and 9.6 years, respectively; (b) Employing $h=48$ with $h=(48 \pm 4)$ and ( $48 \pm 5)$, the synthesized (filtered) modulation of the zonal winds is presented as contour plot at the equator. With heavy solid line, the modulations are shown at $13.6 \mathrm{~km}$ where the phase-shifted pattern is similar to that of the solar flux variation in (a); (c) Analogous to (b), the synthesized temperature variations are shown at the pole, and with heavy line at $10.4 \mathrm{~km}$. In limited attitude regimes, the filtered equatorial zonal wind (b) and temperature (c) modulations of the symmetric AO mimic the solar cycle variability (Figure taken from Mayr et al. [26]).

reviewed and summarized. With realistic height variation of the solar heat source (Figure 4(a)), the model produces QBO zonal wind velocities that vary from about 12 to $20 \mathrm{~m} / \mathrm{s}$ (Figure 4(c)), in phase with the imposed 10-year SC forcing and in qualitative agreement with the observations.

In the mesosphere, the non-linear interaction between the antisymmetric 10year SC variation and the 12-month antisymmetric annual oscillations (AO) of the zonal winds (Figure 8(a)) generates the symmetric Equatorial Annual Os- 
cillation (EAO) that is modulated by the SC (Figure 6). The SC-modulated EAO is the dynamical source or pacemaker for the SC modulation of the QBO. Like the QBO (Figure 4), the EAO propagates down into the lower atmosphere under the influence of wave interactions that amplify the oscillations. And gravity-wave interactions amplify the SC modulations of the QBO (Figure 9(a)) and EAO (Figure 9(b)). The large SC variations in the lower stratosphere are generated by dynamical downward coupling amplified by wave mean flow interactions. Around the equator, the dynamical conditions for the zonal winds are unique [27]. Without the Coriolis force and related meridional circulation, the wave mean flow interactions are very effective because they are only dissipated by eddy diffusion. As a result, the QBO is generated with large zonal winds and large SC variations.

Generated by the meridional circulation, the signature of the SC-modulated QBO zonal winds extend to high latitudes to produce measurable temperature variations in the stratosphere and troposphere (Figure 5(b)). The observed SC effects in polar temperatures have been linked to the equatorial QBO e.g., [3] [7] [9].

The numerical results show that the EAO also generates in the polar region SC variations (Figure 7(b)). The oscillations propagate down from the upper stratosphere and may be related to the Arctic Oscillation, which is a mode of variability that is sensitive to SC influence (e.g., Kodera [43]; Thompson and Wallace [44]; Baldwin and Dunkerton [45]; Ruzmaikin and Feynman [46]; Lee and Hameed [47]; Lee et al. [48]).

NCEP Reanalysis data of the temperature and zonal winds from 1958 to 2006 [39] provide observational evidence of the EAO with SC variations around 11 years [26]. The spectral features of the 48-year data record contain SC signatures with periods of 9.6 and 12 years (Figure 10). And below $20 \mathrm{~km}$, the EAO variations mimic the varying maxima and minima of the $10.7 \mathrm{~cm}$ solar flux (Figure $11)$.

\section{Acknowledgements}

This work was supported by the SRG group at Johns Hopkins University Applied Physics Laboratory, with thanks to Jennifer Skinner.

\section{References}

[1] Salby, M. and Callaghan, P. (2000) Connection between the Solar Cycle and the QBO: The Missing Link. Journal of Climate, 13, 2652-2662. https://doi.org/10.1175/1520-0442(1999)012<2652:CBTSCA $>2.0 . C O ; 2$

[2] Holton, J.R. and Tan, H.C. (1980) The Influence of the Equatorial Quasibiennial Oscillation on the Global Circulation, at $50 \mathrm{MB}$. Journal of the Atmospheric Sciences, 37, 2200-2208. https://doi.org/10.1175/1520-0469(1980)037<2200:TIOTEQ>2.0.CO;2

[3] Labitzke, K. (1982) On the Inter-Annual Variability of the Middle Stratosphere during Northern Winters. Journal of the Meteorological Society of Japan, 60, 124-139. https://doi.org/10.2151/jmsj1965.60.1_124 
[4] Labitzke, K. (1987) Sunspots, the QBO and Stratospheric Temperature in the North Polar Region. Geophysical Research Letters, 14, 535-537. https://doi.org/10.1029/GL014i005p00535

[5] Labitzke, K. and Van Loon, H. (1988) Association between the 11-Year Solar Cycle, the QBO and the Atmosphere. Part I: The Troposphere and Stratosphere in the Northern Hemisphere in Winter. Journal of Atmospheric and Terrestrial Physics, 50, 197-206. https://doi.org/10.1016/0021-9169(88)90068-2

[6] Labitzke, K. and Van Loon, H. (1992) On the Association between the QBO and the Extratropical Stratosphere. Journal of Atmospheric and Terrestrial Physics, 54, 1453-1463. https://doi.org/10.1016/0021-9169(92)90152-B

[7] Dunkerton, T.J. and Baldwin, M.P. (1992) Modes of Interannual Variability in the Stratosphere. Geophysical Research Letters, 19, 49-51.

https://doi.org/10.1029/91GL02869

[8] Baldwin, M.P. and Dunkerton, T.J. (1998) Biennial, Quasi-Biennial, and Decadal Oscillations of Potential Vorticity in the Northern Stratosphere. Journal of Geophysical Research, 103, 3919-3928. https://doi.org/10.1029/97JD02150

[9] Matthes, K., Langematz, U., Gray, L., Kodera, K. and Labitzke, K. (2004) Improved 11-Year Solar Signal in the Freie Universitaet Berlin, Climate Middle Atmosphere Model (FUB-CMAM). Journal of Geophysical Research, 109, D06101. https://doi.org/10.1029/2003JD004012

[10] Palmer, M. and Gray, L. (2005) Modeling the Atmospheric Response to Solar Irradiance Changes Using a GCM with a Realistic QBO. Geophysical Research Letters, 32, L24701. https://doi.org/10.1029/2005GL023809

[11] Hamilton, K. (2002) On the Quasi-Decadal Modulation of the Stratospheric QBO Period. Journal of Climate, 15, 2562-2565. https://doi.org/10.1175/1520-0442(2002)015<2562:OTQDMO >2.0.CO;2

[12] Fischer, P. and Tung, K.K. (2008) A Reexamination of the QBO Period Modulation for the Solar Cycle. Journal of Geophysical Research, 113, D07114. https://doi.org/10.1029/2007JD008983

[13] Mallat, S. (1998) A Wavelet Tour of Signal Processing. Elsevier, New York.

[14] Salby, M. and Callaghan, P. (2006) Relationship of the Quasi-Biennial Oscillation in the Stratospheric Signature of the Solar Cycle. Journal of Geophysical Research, 111, D06110. https://doi.org/10.1029/2005JD006012

[15] Frame, T.H. and Gray, L.J. (2010) The 11-Yr Solar Cycle in ERA-40 Data: An Update to 2008. Journal of Climate, 23, 2213-2222.

https://doi.org/10.1175/2009JCLI3150.1

[16] McCormack, J.P. (2003) The Influence of the 11-Year Solar Cycle on the Quasi-Biennial Oscillation. Geophysical Research Letters, 30, Article ID: 2162. https://doi.org/10.1029/2003GL018314

[17] Cordero, E.C. and Nathan, T.R. (2005) A New Pathway for Communicating the 11-Year Solar Cycle to the QBO. Geophysical Research Letters, 32, L18805. https://doi.org/10.1029/2005GL023696

[18] Matthes, K., Marsh, D.R., Garcia, R.R., Kinnison, D.E., Sassi, F. and Walters, S. (2010) Role of the QBO in Modulating the Influence of the 11 Year Solar Cycle on the Atmosphere Using Constant Forcings. Journal of Geophysical Research, 115, D18110. https://doi.org/10.1029/2009JD013020

[19] Kren, A.C., Marsh, D.R., Smith, A.K. and Pilewskie, P. (2014) Examining the Stratospheric Response to the Solar Cycle in a Coupled WACCM Simulation with an Internally Generated QBO. Atmospheric Chemistry and Physics, 14, 4843-4856. 
https://doi.org/10.5194/acp-14-4843-2014

[20] Mayr, H.G., Mengel, J.G. and Wolff, C.L. (2005) Wave-Driven Equatorial Annual Oscillation Induced and Modulated by the Solar Cycle. Geophysical Research Letters, 32, L20811. https://doi.org/10.1029/2005GL023090

[21] Mayr, H.G., Mengel, J.G., Wolff, C.L. and Porter, H. (2006) QBO as Potential Amplifier of Solar Cycle Influence. Geophysical Research Letters, 33, L05812. https://doi.org/10.1029/2005GL025650

[22] Mayr, H.G., Mengel, J.G., Wolff, C.L., Huang, F.T. and Porter, H.S. (2007) The QBO as Potential Amplifier and Conduit to Lower Altitudes of Solar Cycle Influence. Annales Geophysicae, 25, 1071-1092.

https://doi.org/10.5194/angeo-25-1071-2007

[23] Mayr, H.G., Mengel, J.G., Huang, F.T. and Nash, E.R. (2007) Equatorial Annual Oscillation with QBO-Driven 5-Year Modulation in NCEP Data. Annales Geophysicae, 25, 37-45. https://doi.org/10.5194/angeo-25-37-2007

[24] Mayr, H.G., Mengel, J.G., Huang, F.T., Talaat, F.R., Nash, E.R. and Reddy, C.A. (2008) Stratospheric Semi-Decadal Oscillations in NCEP Data. Annales Geophysicae, 26, 2143-2157. https://doi.org/10.5194/angeo-26-2143-2008

[25] Mayr, H.G. and Lee, J.N. (2016) Downward Propagating Equatorial Annual Oscillation and QBO Generated Multi-Year Oscillations in Stratospheric NCEP Reanalysis Data. Journal of Atmospheric and Solar-Terrestrial Physics, 138, 1-8. https://doi.org/10.1016/j.jastp.2015.11.016

[26] Mayr, H.G., Mengel, J.G., Huang, F.T. and Nash, E.R. (2009) Solar Cycle Signatures in the NCEP Equatorial Annual Oscillation. Annales Geophysicae, 27, 3225-3235. https://doi.org/10.5194/angeo-27-3225-2009

[27] Lindzen, R.S. and Holton, J.R. (1968) A Theory of the Quasi-Biennial Oscillation. Journal of the Atmospheric Sciences, 25, 1095-1107. https://doi.org/10.1175/1520-0469(1968)025<1095:ATOTQB >2.0.CO;2

[28] Chan, K.L., Mayr, H.G., Mengel, J.G. and Harris, I. (1994) A "Stratified" Spectral Model for Stable and Convective Atmospheres. Journal of Computational Physics, 113, 165-176. https://doi.org/10.1006/jcph.1994.1128

[29] Chan, K.L., Mayr, H.G., Mengel, J.G. and Harris, I. (1994) A Spectral Approach for Studying Middle and Upper Atmospheric Phenomena. Journal of Atmospheric and Terrestrial Physics, 56, 1399-1419. https://doi.org/10.1016/0021-9169(94)90077-9

[30] Mengel, J.G., Mayr, H.G., Chan, K.L., Hines, C.O., Reddy, C.A., Arnold, N.F. and Porter, H.S. (1995) Equatorial Oscillations in the Middle Atmosphere Generated by Small Scale Gravity Waves. Geophysical Research Letters, 22, 3027-3039. https://doi.org/10.1029/95GL03059

[31] Mayr, H.G., Mengel, J.G., Chan, K.L. and Huang, F.T. (2010) Middle Atmosphere Dynamics with Gravity Wave Interactions in the Numerical Spectral Model: Zonal-Mean Variations. Journal of Atmospheric and Terrestrial Physics, 72, 807-828. https://doi.org/10.1016/j.jastp.2010.03.018

[32] Mayr, H.G., Mengel, J.G., Chan, K.L. and Huang, F.T. (2011) Middle Atmosphere Dynamics with Gravity Wave Interactions in the Numerical Spectral Model: Tides and Planetary Waves. Journal of Atmospheric and Solar-Terrestrial Physics, 73, 711-730. https://doi.org/10.1016/j.jastp.2011.01.019

[33] Hines, C.O. (1997) Doppler-Spread Parameterization of Gravity-Wave Momentum Deposition in the Middle Atmosphere, 1, Basic Formulation. Journal of Atmospheric and Solar-Terrestrial Physics, 59, 371-386. https://doi.org/10.1016/S1364-6826(96)00079-X 
[34] Hines, C.O. (1997) Doppler-Spread Parameterization of Gravity-Wave Momentum Deposition in the Middle Atmosphere, 2, Broad and Quasi Monochromatic Spectra, and Implementation. Journal of Atmospheric and Solar-Terrestrial Physics, 59, 387-400. https://doi.org/10.1016/S1364-6826(96)00080-6

[35] Hines, C.O. (2001) Theory of the Eulerian Tail in the Spectra of Atmospheric and Oceanic Internal Gravity Waves. Journal of Fluid Mechanics, 448, 289-313. https://doi.org/10.1017/S0022112001005973

[36] Hines, C.O. (2002) Nonlinearities and Linearities in Internal Gravity Waves of the Atmosphere and the Oceans. Geophysical \& Astrophysical Fluid Dynamics, 96, 1-30. https://doi.org/10.1080/03091920290018826

[37] Mayr, H.G., Mengel, J.G., Hines, C.O., Chan, K.L., Arnold, N.F., Reddy, C.A. and Porter, H.S. (1997) The Gravity Wave Doppler Spread Theory Applied in a Numerical Spectral Model of the Middle Atmosphere, 1, Model and Global Scale Seasonal Variations. Journal of Geophysical Research, 102, 26077-26092. https://doi.org/10.1029/96JD03213

[38] Mayr, H.G., Mengel, J.G., Talaat, E.R., Porter, H.S. and Chan, K.L. (2004) Modeling Study of Mesospheric Planetary Waves: Genesis and Characteristics. Annales Geophysicae, 22, 1885-1902. https://doi.org/10.5194/angeo-22-1885-2004

[39] Kalnay, E., Kanamitsu, M., Kistler, R., Collins, W., Deaven, D., Gandin, L., Iredell, M., Saha, S., White, G., Woollen, Zhu, Y., Leetmaa, A., Reynolds, R., Chelliah, M., Ebisuzaki, W., Higgins, W., Janowiak, J., Mo, K.L., Ropelewski, C., Wang, J., Jenne, R. and Joseph, D. (1996) The NCEP/NCAR 40-Year Reanalysis Project. Bulletin of the American Meteorological Society, 77, 437-471. https://doi.org/10.1175/1520-0477(1996)077<0437:TNYRP>2.0.CO;2

[40] Kalnay, E. (2003) Atmospheric Modeling, Data Assimilation, and Predictability. Cambridge University Press, Cambridge.

[41] Huesmann, A.S. and Hitchman, M.H. (2001) The Stratospheric Quasi-Biennial Oscillation in the NCEP Reanalysis: Climatological Structure. Journal of Geophysical Research, 106, 11,859-11,874. https://doi.org/10.1029/2001JD900031

[42] Huesmann, A.S. and Hitchman, M.H. (2003) The 1978 Shift in the NCEP Reanalysis Stratospheric Quasi-Biennial Oscillation. Geophysical Research Letters, 30, 1048. https://doi.org/10.1029/2002GL016323

[43] Kodera, K. (1995) On the Origin and Nature of the Inter-Annual Variability of the Winter Stratospheric Circulation in the Northern Hemisphere. Journal of Geophysical Research, 100, 14077-14088. https://doi.org/10.1029/95JD01172

[44] Thompson, D.W.J. and Wallace, J.M. (1998) The Arctic Oscillation Signature in the Wintertime Geopotential Height and Temperature Fields. Geophysical Research Letters, 25, 1297-1300. https://doi.org/10.1029/98GL00950

[45] Baldwin, M.P. and Dunkerton, T.J. (1999) Propagation of the Arctic Oscillation from the Stratosphere to the Troposphere. Journal of Geophysical Research, 104, 30937-30946. https://doi.org/10.1029/1999JD900445

[46] Ruzmaikin, A. and Feynman, J. (2002) Solar Influence on a Major Mode of Atmospheric Variability. Journal of Geophysical Research, 107, 4209. https://doi.org/10.1029/2001JD001239

[47] Lee, J.N. and Hameed, S. (2007) The Northern Hemisphere Annular Mode in Summer: Its Physical Significance and Its Relation to Solar Activity Variations. Journal of Geophysical Research, 112, D15111. https://doi.org/10.1029/2007JD008394

[48] Lee, J.N. and Hameed, S. and Shindell, D.T. (2008) Northern Annular Mode in 
Summer and Its Relation to Solar Activity Variations in the GISS Model E. Journal of Atmospheric and Solar-Terrestrial Physics, 70, 730-741.

https://doi.org/10.1016/j.jastp.2007.10.012 